noisy and troublesome acute cases and irrecoverable chronic ones; and the third for convalescents. Best of all, there is a fourth branch, in some ways the main and central onenamely, an out-patient department and a ward for inpatients at a great general hospital, the Middlesex.

I mention this scheme not to discuss it, but to show what can be and is being done in the face of quite extraordinary difficulties. I am glad to think that it is one of the registered hospitals which has taken the lead in this way, and $I$ hope that under its enlightened and far-seeing head, Dr. Gilmour, the new St. Luke's will have the success which it deserres.

I have felt the responsibility and the difficulty of preparing this paper very keenly. I have left unsaid a great cleal that might well have been included in our subject, but the whole matter is such a far-reaching one that if discussion is to be fruitful we must limit its range.

I have therefore-here and there with reluctancetouched upon the points which seem to me most to need frank and courageous discussion. And I want our dis\&ussion to be fruitful. There is so much to do, and there are so many difficulties in the way. But it is to the general body of the profession that we may fairly look for help. There could be no better outlet for the organized activity of the profession and of this Association than a combined effort to bring just a little more science, a little broader humanity, a little more practical good sense, into our dealings with sufferers from the saddest of all human ills.

\section{THE X-RAY TREATMENT OF WOUNDS.*}

\section{Professor Dr. LEOPOLD FREUND,} VIENNA.

Ir is the experience of many of the older radiologists that the healing, not only of carcinomatous, sarcomatous, actinomycotic, venereal, tuberculous, and other ulcers, but also of old, neglected, sluggish, or badly healing wounds, can be hastened by the influence of $x$ rays. This agrees with the experience of those authors who used the sun's rays, or powerful sources of artificial light, for the same purpose. It was the observation of the effect of light on an old wound, the result of a stab with a knife, which induced our distinguished colleague, Dr. Bernhard of St. Moritz, to introduce the sun's rays as a healing factor into therapy in the year 1902.

It is difficult to decide whether this beneficial influence is due to the stimulating effect of small doses of $x$ rays on the functions and growth of the cells, or whether it is to be traced back to the elimination by $x$ rays of an antagonistic factor which delays cicatrization. In my opinion, which is also shared by Professor Arzt and Dr. Fuhs, the question whether the increase in proliferation is caused by direct or indirect stimulation of the activity of the cells is of less importance, for all practical purposes, than the fact that undoubtedly small doses of $x$ rays have a stimulating effect on badly healing wounds.

But it is not this subject, interesting and of practical importance though it certainly is, to which I wish to direct your consideration. I desire to solicit your interest for one particular indication for $x$ rays, which would appear to be little appreciated in your country-the $x$-ray treatment of fresh and open wounds. As long ago as 1898 $I$ noticed the beneficial influence of $x$ rays on keloids and bad scars. In a later histological experiment on a very large keloidal scar, I observed that the hyperplasia of the connective tissue arose from the numerous young round cells and spindle cells clustered round the blood vessels. The idea at once occurred to me that it might be possible to prevent the formation of keloid by exposing to the destroying influence of $x$ rays those groups of cells which, on account of their youth, are particularly sensitive. Since then, after complete excision of tumours in a number of people who showed a tendency to keloid formation, instead of stitching up the wounds or covering them. with skin

* A paper given by invitation at the Annual Mecting of the British Medical Association in Marchester. July, 1929 grafts, $I$ administered small doses of $x$ rays to the open wounds, the bleeding of which had been stopped lege artis. The $x$-ray dose was administered immediately and repeated on several successive days; without exception very good results were obtained. As a consequence I did not hesitate to employ this method in other pathological conditions for which $I$ considered it suitable; in this work I have enjoyed the valued collaboration of Professor $\mathbf{H}$. Salzer.

The following conditions were treated: circumscribed patches of lupus vulgaris, epitheliomata, rodent ulcers, keloids, and pigmented naevi.

This method offers various advantages over other methods of treatment of lupus vulgaris and malignant new growtlis. When such pathological masses of tissue are excised the $x$ rays do not have to destroy these tissues, a task which they cannot accomplish as quickly as a knife. Masses of tissue of varying thicknesses are removed, which would otherwise weaken the rays by absorbing them on their way to the base of the lesion. Thus the $x$-raying of the open wound after operation renders the operation more effective. If some traces of the disease are left in the wound, they will be attacked more intensively than when the wound is stitched up. If, in spite of excision and subsequent treatment with $x$ rays, some remaining trace of the disease gives rise to a circumscribed recurrence, this may be removed easily and quickly by the same method. The thin delicate soft scar offers only a slight resistance to the breaking through of the new growth to the outside. This constitutes a very important advantage over large wounds which have been stitched or grafted. Such wounds often become so hard, thick, and oedematous that they offer insuperable obstacles to the breaking through of the infiltration which is growing beneath them, and which consequently takes the line of least resistance and spreads beneath the scar. In other words, a thick scar encourages the propagation of the disease in the body of the patient.

As the cosmetic results are excellent, the resulting sca $: 8$ being not inferior to those obtained with Finsen light, ve used this method in a large pigmented naevus, in which excision with subsequent stitching or Thiersch grafting, would certainly not have given such a good cosmetic result as that which we obtained.

The method offers, in addition, in lupus vulgaris and malignant processes, the great advantage of shortening considerably the duration of treatment, especially that of the required $x$-ray treatment. For instance, in lupus vulgaris it dispenses with the frequent application of $x$ rays, which would be necessary if the lesion were not previously excised, and we have all had experience of the dangers which may result from continued $x$-ray treatment, By using my method a patch of lupus vulgaris the size of the palm of the hand can be fully healed in six to eight weeks.

The application of this method has its limits, depending upon the localization and extent of the lesion; within these limits there still remains a wide scope for fruitful work.

Wounds in situations where the skin remains stretched are the most suitable for this kind of treatment. Near joints or folds, where the edges of the wounds approach one another whilst in movement, the resulting scars are only satisfactory if movement is eliminated by a firm bandage during the period of healing. Even a very extensive wound following excision is not an obstacle to the formation of a good scar. For instance, I saw a circular wound with a diameter of $10 \mathrm{~cm}$. over the great trochanter, which resulted in a perfect scar. According to my experience the duration of healing of wounds after $x$ rays is certainly not longer than it would be without $x$ rays.

As a result of an experiment on an animal which I performed with Dr. Peach of Manchester during her stay in Vienna, we found that a fresh wound $x$-rayed with our therapeutic dose was healed a little carlier than an un- $x$-rayed wound of exactly the same area and depth, symmetrically situated in the same animal. This observation. was recently confirmed by a communication from H. Suichi Fukase of the Holzknecht Laboratory. ${ }^{1}$

Herr Glocker found that wounds healed more slowly after $x$ rays; probably this was due to the dosage given. ${ }^{2}$ The close which we usually apply is a little higher than an 
epilation dose, about 6 to $7 \mathrm{H}$. We distribute it over six or seven sittings, which take place at intervals of two to three dars. It would appear that unfiltered rays of 6 to $7 \mathrm{H}$. hardness are more effieient than strongly filtered hard rays.

We may note in passing that Popoff and Teskoff, experimenting on the hastening of the regeneration of wounds, found that $\mathrm{MgCl}_{2}$ was especially efficient, particularly at intervals of one to two days. ${ }^{3}$

Cases where the lesion is situated in folds or angles of the skin are not suitable for this meihod-for example, at the upper end of the naso-labial folds, near the alae of the nose, in the angle behind the lobes of the ears, and similar situations. After the excision of such a lesion a cavernous wound results, the inner surface of which cannot be reached in its entire extent by the $x$ rays. Very extensive lesions are also unsuitable.

Herr Franz Freund recommends the previous $x$-raying of wounds (loco citato), because, in his opinion, the beneficial effects of $x$ rays on fresh wounds is due to the fact that they hinder inflammation and the development of the exudation of leucocytes. But I cannot see that this proposal would improve my method, because I consider it a somewhat doubtful procedure to operate on an area of the skin which has been $x$-rayed shortly beforehand, as such a skin sometimes reacts to every form of trauma with an $x$-ray dermatitis. Further, I do not consider it reasonable previously to $x$-ray a portion of skin which is to be immediately excised.

Bearing on this point the communication of Richard Sparmanns is noteworthy. ${ }^{4}$ He states that in Malays, who have a very strong tendency to excessive hrperplasia of the connective tissue, and who are liable to keloid formation, the prophylactic $x$-raying of the area before the operation, or $x$-raying immediately after the removal of the stitches (that is, where the open wound is not $x$-rayed), is very often useless.

In conclusion, I thank you for the honour which your Association has done me by its kind invitation, and $\mathbf{I}$ am very sorry that it is impossible for me personally to be present. I am very grateful to my eminent colleague and old friend, Dr. Lancashire, for delivering this paper in my absence.

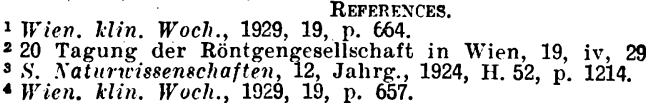

\section{THE CAUSES AND TREATMENT OF PERSistent NASAL CATARRH, PARTICULARLY IN CHILDREN.*}

\author{
BY
}

DAN McKENZIE, M.D., F.R.C.S.ED., BURGEON, CENTRAL LONDON THROAT AND EAR HOSPITAL.

THE term " nasal catarrh" has of late years become a popular expression covering a large variety of pathological processes. It differs from that other popular disease " a cold in the head" in being chronic, although to be sure nasal catarrh may start with a cold in the head, and its course is generally punctuated by recurrent bouts of the same malady. Translating this into medical phraseology we may say that a cold in the head is an acute rhinitis, and nasal catarrh a chronic rhinitis, both being characterized by a discharge of mucus or muco-pus from the nose, and by inflammatory swelling of the turbinals, particularly of the inferior, leading to nasal obstruction. In the acute disease the symptoms are more severe, and the headache, malaise, and muscular languor betoken the presence of toxaemia. It is, besides, an infectious disease; at least in certain circumstances it behaves as such. (Paroxysmal rhinorrhoea is, of course, out of bounds in the present discussion. It is not nasal catarrh, although popularly it goes by that name.) ${ }^{*}$ Read in opening a discussion in the Section of Oto-Rhino-LaryngoManchester, 1929.
Rhinitis, whether acute or chronic, is due to an infection of the nasal mucosa. But when we ask by what microorganism it is induced we are presented with an embarrassment of riches, since almost any of the pyogenes may be present, alone or in company. But inasmuch as the pneumococcus is the most constant, it is natural to infer that that organism is probably the pioneer of the invaders. The fact, however, that during the early hours of an acute catarrh the nasal secretion contains but few bacteria of any kind has led to the surmise that the first onslaught is made by an ultramicrescopic organism, and that those usually found present are sccondary infections.

From the clinical, as distinct from the bacteriological, point of view, we may divide our cases into two groups: first, those in which the catarrh can be traced to a local cause or focus; and secondly, those in which no such local cause can be detected.

The chief local causes in children are, first and foremost, adenoids, with or without hypertrophied inferior turbinals and tonsils, and, secondly, nasal sirus suppuration. In adults the same local causes exist, although with a different relative frequency, sinus suppuration being more, and adenoids less, common than in children, while, in addition, deviations of the nasal septum lead on to nasal catarrh frequently in adults and seldom in children.

Our discussion refers particularly to nasal catarrh in children, and at once the mind turns to the all-important if well-worn subject of adenoids.

What is the relationship between nasal catarrh and adenoids? Are they both expressions of one and the same infection? Or does the one induce the other? And, if so, which is the primary? Here we find ourselves up against the old but still unsolved problem of the cause of adenoids. In endearouring to find a way out of this maze of questions all we have to guide us, as far as I know, is clinical observation. Bacteriology is silent, and experimental pathology is not very helpful. But let us see what we can gather from our observation of the disease.

First of all, I have been informed by Dr. Alice Vance Knox, who has a large experience of welfare work, that nasal catarrh is one of the earliest of life's maladies, appearing quite frequently in infants only a fortnight old; and the same observation has been made by $\mathbf{R}$. C. Clarke, who remarks also that the nasal catarrh is always associated in infants with bronchial catarrh. Now it is well known that lymphoid tissue can be demonstrated in the nasopharynx at birth, but it is rarely bulky enough to require removal until months, and more often years, later. This seems to indicate that the catarrhal infection of the nose precedes the pathological hypertrophy of the lymphoid masses.

It will be remembered also how Dr. P. Watson-Williams has suggested that adenoids are due to chronic bacterial infection of the nose. In criticism of this view we sometimes hear it said that lymphoid hypertrophy as a reaction to sepsis is a novel, hitherto unknown phenomenon. But it is by no means novel or unknown. What is the naturo of the enlarged cervical glands that accompany chronic hypertrophy of the pharyngeal tonsils? 'The members of the whole group of enlarged lymphoid aggregations-adenoids, tonsils, and lymphatic glands-are quite obviously related to each other and to some low form of chronic sepsis, located in themselves no doubt. But from what primary source did it emanate if not from the nose? Thus, accord. ing to this view, adenoids is merely an incident in the course of chronic rhinitis.

-But, attractive though this explanation may be, it does not account for all the phenomena. If chronic nasal sepsis can in this way induce hypertrophy of the nasopharyngeal tonsil, why are not adenoids also produced in adults with chronic nasal catarrh? We cannot answer this question except by assuming that there is no lymphoid tissue to undergo hypertrophy in the nasopharynx of adults-and that is not the case.

In children adenoids sometimes recur after they have been quite efficiently remored. Their cause must therefore be persisting. Again, is it chronic rhinitis? But once more, what is the explanation of their non-recurrence in adults after remoral? 